\title{
Cleavage classification: categorizing a vital feminine aesthetic landmark
}

\author{
Muhammad Adil Abbas Khan', Ammar Asrar Javed², Nigel Mercer ${ }^{3}$ \\ ${ }^{1}$ Plastic Surgery, NHS Lothian, Edinburgh EH1 3EG, UK. \\ ${ }^{2}$ Department of Surgery, Johns Hopkins Hospital, Baltimore, MD 21287, USA. \\ ${ }^{3}$ Plastic Surgery, Bristol Plastic Surgery, Bristol BS1 4LF, UK.
}

Address for correspondence: Dr. Ammar Asrar Javed, Department of Surgery, Johns Hopkins Hospital, 600 N, Wolfe Street/Blalock 611, Baltimore, MD 21287, USA. E-mail: ajaved1@jhmi.edu.

Breast cleavage is defined by the International Federation of Associations of Anatomists (IFAA), as the space present between a woman's breasts. The width of the inter-mammary cleft is defined by the distance between the points of attachment of the breast tissue to the periosteal tissue..$^{[1-3]}$

Cleavage is associated with femininity and its exposure to varying degrees by women across the world can be aimed to heighten both self-image and physical attractiveness. ${ }^{[4,5]}$ The use of Décolletage in dresses dates back to the 11th century, when an aesthetic cleavage was perceived as a sign of beauty, wealth and social stature. $^{[6,7]}$ Corsets were later introduced in the 16th century and their use was primarily aimed at pushing the breasts upwards to give a fuller cleavage. ${ }^{[8,9]}$ In more recent times, specialized brassieres (push-up bras) with various forms of paddings (falsies) have become the more popular and comfortable option. Other conservative methods of making the cleavage more prominent include skin pulling techniques, taping, use of glued shapes, under bras, adhesive gels and the use of makeup.

Breast augmentation is the most commonly performed cosmetic procedure in the US, and in recent years a great increase has been reported in the number of these procedures performed annually. ${ }^{[10]}$ Women requesting breast augmentation often request a specific form of cleavage enhancement and it is common for potential patients to bring photographs of desired cleavage shapes and appearances. A plastic surgeon can be put in a

\begin{tabular}{|l|l|}
\hline \multicolumn{2}{|c|}{ Access this article online } \\
\hline Quick Response Code: & Website: \\
\hline & http://par.oaepublish.com/ \\
\cline { 2 - 3 } & DOI: \\
\hline
\end{tabular}

challenging position when the patient's expectations are not realistic; therefore a strong communication of ideas is necessary. ${ }^{[1]}$ Titration of the subjective expectations of the patients, while aiming for satisfactory aesthetic outcomes, becomes a dilemma for the surgeon.

It is therefore important to devise a more objective method of assessing the preoperative anatomy and classifying the postoperative expectations of a woman wanting an augmentation. Much work has been done to classify breasts based on their shapes, contours and sizes; ${ }^{[12-15]}$ however, despite cleavage being an equally important determinant of one's beauty, there has not been any reported efforts towards classification of cleavage. ${ }^{[16]}$

Body postures, alternate postures, bras and garments can influence the appearance of the cleavage and hence during the assessment stage, a female patient's natural cleavage shape should be assessed in the "neutral" position with her arms by her sides and her hands on the back as she slightly leans forward. We identified different shapes of cleavage that women present with and classified them based on the "anterio-posterior" or "frontal” view (surgeon's perspective and patient's mirror view) as well as a "cranio-caudal" or "bird's eye" view (patient's direct visual perspective).

\section{ANTEROPOSTERIOR OR FRONTALVIEW}

From a frontal perspective, the shape of the cleavage has

This is an open access article distributed under the terms of the Creative Commons Attribution-NonCommercial-ShareAlike 3.0 License, which allows others to remix, tweak and build upon the work non-commercially, as long as the author is credited and the new creations are licensed under the identical terms.

For reprints contact: service@oaepublish.com

How to cite this article: Khan MAA, Javed AA, Mercer N. Cleavage classification: categorizing a vital feminine aesthetic landmark. Plast Aesthet Res 2016;3:36-8.

Received: 13-08-2015; Accepted: 24-11-2015 
potential shapes based on the proximity of the breasts to each other and on the width of the cleavage at the inferior and superior poles. These can be classified as the "cocktail glass", the "champagne glass", the "hourglass" and the "hiball glass".

The "cocktail glass" appearance, as the name suggests, is the shape of the cleavage where the breasts are in close proximity and there is no space between them in the inferior half of the cleavage. The superior part of the cleavage acutely curves away from the breasts in a relatively linear fashion

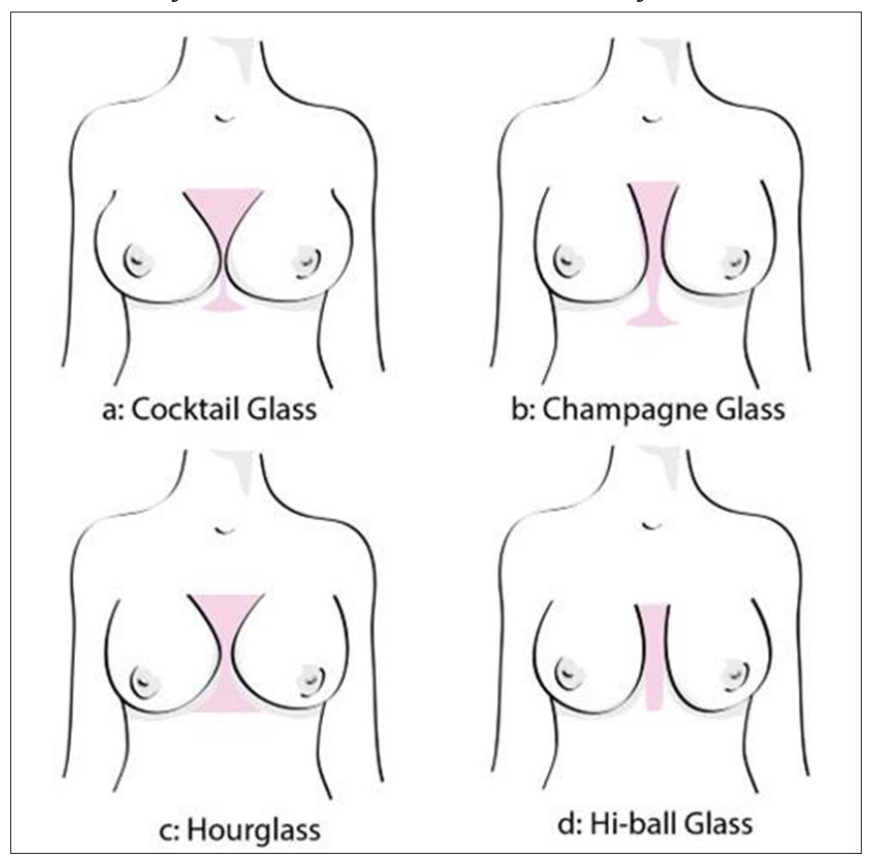

Figure 1: Cleavage classification based on anteroposterior point of view

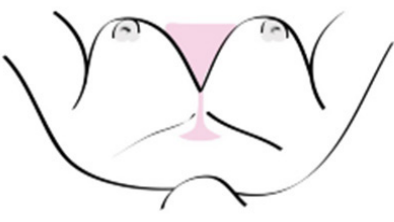

a: Cocktail Glass
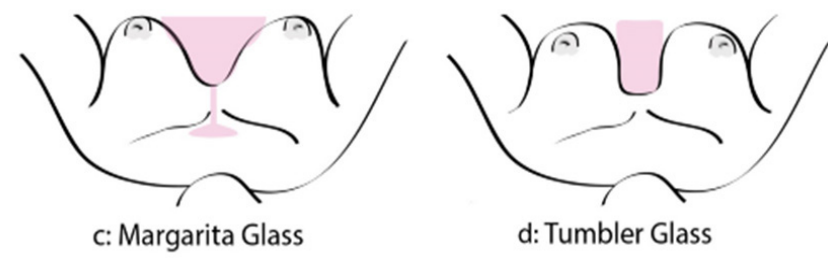

d: Tumbler Glass

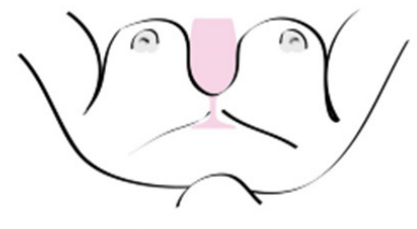

b: Goblet Glass
Figure 2: Cleavage classification based on craniocaudal point of view

leaving a wider, exposed region of the cleavage [Figure $1 \mathrm{a}]$.

A "champagne glass" appearance represents a cleavage in which though the breasts are in close proximity they are not in contact leaving a visible region between the breasts through the total length of the cleavage. The width in the inferior half remains short and constant, while that of the superior part increases considerably and the contours bend away from the midline. This results in a wider cleavage in the superior half when compared to cocktail glass cleavage [Figure 1b].

The "hourglass" shape defines a cleavage in which the medial contours of the breast almost touch at a simple point of contact. When compared to the "cocktail glass" and "champagne glass" appearance, breasts with an hourglass cleavages have less proximity between them. The width of the cleavage is minimum at the midpoint between superior and inferior poles of the cleavage and increases almost symmetrically towards both these ends [Figure 1c].

The shape that defines a "hi-ball glass" cleavage is one where breasts are at a considerable distance from each other. The shape of this cleavage is such that the width of the cleavage stays considerably constant through its length [Figure 1d].

\section{“CRANIOCAUDAL” OR “BIRD'S EYE”VIEW}

To classify cleavages according to this view, the breasts and cleavage should be observed from above the head of a patient with the patient in a neutral position. From this view, the cleavage can be classified based on its width as well as the proximity of the breasts to each other into four shapes: the "cocktail glass", "goblet glass", "margarita glass" and "tumbler glass".

The "cocktail glass" appearance is one in which the breasts are in close proximity to each other and there is a point in the cleavage where the breasts meet, leaving no visible gaps between the breasts. The breasts then curve anteriolaterally in a relatively linear manner towards the areola. The shape formed by this cleavage is similar to a cocktail glass [Figure 2a].

Similarly there is the "goblet glass" appearance which is a result of a close proximity of the breasts to each other, while having no point of contact between them. The shape of the cleavage is such that it forms a curved shape in the center of the inter-mammary cleft which then curves antero-laterally towards the areola. When compared to the cocktail glass appearance the curves are more pronounced as compared to more linear ones in the earlier [Figure $2 \mathrm{~b}$ ].

The "margarita glass" cleavage is similar to both the cocktail glass and goblet glass cleavages with the exception that the width of the inter-mammary cleft is wider and the medial breast is more curvy and tapers antero-laterally more acutely [Figure 2c].

Lastly the "tumbler glass" appearance is one where the breasts are further apart leaving a greater space between them. The medial curves of the breasts descend posteromedially in a sharp manner and thus do not extend further towards the midline. This leaves a flat region in the cleavage representing the region superficial to the sternum that lacks breast tissue. The shape is such that instead of being curved the cleavage has a rectangular or "boxy" appearance [Figure $2 \mathrm{~d}$ ]. 
This classification system is applicable to all breast sizes. It is based on the appearance of the cleavage and takes in to account the width of the cleavage at the superior and inferior poles of the breast, and the midpoint between them. In women with smaller breasts the cleavage will be more pronounced, and different than that of women with fuller breasts. However, the authors believe that even in women with smaller breasts the shape of the cleavage should vary according to our classification system. In this cohort of patients the more prevalent classes would be the hour glass, and the hi-ball glass (anteroposterior view) and the margarita glass, and the tumbler glass (craniocaudal view). Similarly for women with larger breasts one would expect to observe cocktail glass and champagne glass (anteroposterior view) and cocktail and goblet glass (craniocaudal view).

Patient satisfaction after breast augmentation is variable and some studies have reported that not all patients are satisfied with their postoperative outcomes..$^{[5,10,17]}$ It depends on multiple aspects of the appearance of the breasts including their shape, size, contours as well as the appearance of the cleavage. Patients are unique and any given cleavage may not necessarily fit one particular classification. However, this classification based on various everyday shapes of glasses, can be used by surgeons to help patients acquire an objective understanding regarding their expectations from surgery. Surgeons can use this classification system preoperatively to discuss the expectations of patients regarding the appearance of their cleavage in addition to their breasts. If patients desire a certain type of cleavage after their augmentation the surgeon can modify their choice of implants and their surgical technique accordingly. A breast augmentation procedure as well as the choice of implant may then be altered, taking into consideration not only the desired increase or decrease in breast size but also the desired modification of cleavage appearance.

Though the proposed classification is based on personal observations and the nomenclature of glasses, we believe that if used in conjunction with the existing practices of breast augmentation, it will result in an improved aesthetically pleasing outcome leading to better patient satisfaction with the results of the augmentation. Our proposed classification should be further explored by formal studies that analyze both preoperative and postoperative patient satisfaction. This analysis could be either a twodimensional e.g. using photographs or three-dimensional analysis ${ }^{[18,19]}$ and lead to better understanding of role of preoperative and postoperative cleavage morphology in patient satisfaction.

\section{Financial support and sponsorship}

Nil.

\section{Conflicts of interest}

There are no conflicts of interest.

\section{REFERENCES}

I. Oliver R. I'll boost your boobs or go bust! Plastic Surgery 10I, 2007. Available from: http://plasticsurgeryl0I.blogspot.com/2007_08_0I_ archive.html. [Last accessed on November 24, 20I5]

2. West's federal supplement (First Series). Victoria, Minnesota: West Publishing Co; 1990. p. 994

3. Eisenberg T, Eisenberg J. The scoop on breasts: a plastic surgeon busts the myths. Ist ed. Philadelphia: Incompra Press; 2012.

4. Hsu VM, Tahiri Y, Wes AM, Yan C, Selber JC, Nelson JA, Kovach SJ, Serletti JM, Wu LC. Does breast reconstruction impact the decision of patients to pursue cosmetic surgery? Ann Plast Surg 2014;73:SI44-8.

5. Gladfelter J, Murphy D. Breast augmentation motivations and satisfaction: a prospective study of more than 3,000 silicone implantations. Plast Surg Nurs 2008;28: 170-4.

6. Gernsheim A. Victorian and Edwardian Fashion: A Photographic Survey (Dover Fashion and Costumes). New York: Dover Publications, 1982.

7. Morris D. The naked woman: a study of the female body. Reprint edition. New York: St. Martin's Griffin; 2007.

8. Spooner C. Fashioning gothic bodies. Manchester: Manchester University Press; 2004. p. 28.

9. Condra J.The greenwood encyclopedia of clothing through world history. Westport, Connecticut: Greenwood Publishing Group; 2008. p. 152.

10. McCarthy CM, Cano SJ, Klassen AF, Scott A, Van Laeken N, Lennox PA, Cordeiro PG, Pusic AL. The magnitude of effect of cosmetic breast augmentation on patient satisfaction and health-related quality of life. Plast Reconstr Surg 2012;130:218-23.

II. Dini GM, Gozzano R, Ferreira RB, Faria M, Farinazzo M, Ferreira LM. Mirror, mirror on the wall, which breast is bigger of them all. Plast Reconstr Surg Glob Open 20I4;2:el05.

12. von Heimburg D, Exner K, Kruft S, Lemperle G. The tuberous breast deformity: classification and treatment. Br J Plast Surg 1996; 49:339-45.

13. India M. Breasts - structures and types. Available from: http://www. medindia.net/patients/patientinfo/breasts-structures-and-types-breasttypes.html. [Last accessed on November 24, 20I5]

14. Room H. Classify your breast. Available from: http://www.herroom.com/ breast-shape,336,30.html. [Last accessed on November 24, 20I5]

15. Chasan PE.A new breast shape classification. Plast Surg Pract 2011.

16. Kolker AR, Collins MS. Reply: tuberous breast deformity: classification and treatment strategy for improving consistency in aesthetic correction. Plast Reconstr Surg 2015;136:e269-70.

17. Young VL, Nemecek JR, Nemecek DA. The efficacy of breast augmentation: breast size increase, patient satisfaction, and psychological effects. Plast Reconstr Surg 1994;94:958-69.

18. Galdino GM, Nahabedian M, Chiaramonte M, Geng JZ, Klatsky S, Manson P. Clinical applications of three-dimensional photography in breast surgery. Plast Reconstr Surg 2002; I 10:58-70.

19. Kovacs L, Eder M, Hollweck R, Zimmermann A, Settles M, Schneider A, Udosic K, Schwenzer-Zimmerer K, Papadopulos NA, Biemer E. New aspects of breast volume measurement using 3-dimensional surface imaging. Ann Plast Surg 2006;57:602-10. 